\title{
Balloon-Assisted Endoscopy: A Powerful Tool for Complete Colonoscopy
}

\author{
Kyung Hwan Song and Beom Jae Lee \\ Department of Gastroenterology, Korea University Guro Hospital, Seoul, Korea
}

See "Double-Balloon Endoscopy after Incomplete Colonoscopy and Its Comparison with Computed Tomography Colonography" by Carlijn Hermans, Dennis van der Zee, Lennard Gilissen, on page. 66-71.

Colonoscopy is an essential diagnostic and therapeutic tool for colonic diseases, including adenoma and cancer. ${ }^{1}$ Needless to say, cecal intubation rate is the most important quality indicator of colonoscopy examination, and failure of cecum reach is closely related to post colonoscopy colorectal cancer (CRC). The American Society for Gastrointestinal Endoscopy guideline recommends that the target cecal intubation rate in screening colonoscopy is $>95 \%{ }^{2}$ Various factors have been suggested as affecting the cecal intubation rate. These factors include female sex, old age, obesity, poor bowel preparation, and prior abdominal surgery and diverticular disease. ${ }^{3-5}$ How can we overcome colonoscopic failure? Balloon-assisted colonoscopy can be a candidate solution for this problem. The advent of balloon-assisted enteroscopies has led to visualize the deep portion of the small bowel, and various small bowel diseases have been diagnosed and investigated using this technique. ${ }^{6}$ Owing to their ability of bowel fixation and shortening of bowel loops with additional balloon and overtube, indications of these techniques were extended to colonoscopy in patients with complicated bowel loops, endoscopic retrograde

Received: January 16, 2018 Revised: January 18, 2018

Accepted: January 19, 2018

Correspondence: Beom Jae Lee

Department of Gastroenterology, Korea University Guro Hospital, 148 Gurodong-ro, Guro-gu, Seoul 08308, Korea

Tel: +82-2-2626-3004, Fax: +82-2-853-1943, E-mail: L85210@korea.ac.kr

(cc) This is an Open Access article distributed under the terms of the Creative Commons Attribution Non-Commercial License (http://creativecommons.org/ licenses/by-nc/3.0) which permits unrestricted non-commercial use, distribution, and reproduction in any medium, provided the original work is properly cited. cholangiopancreatography in patients with altered anatomy, and endoscopic submucosal dissection (ESD) for colorectal lesions that are difficult to be resected en bloc. ${ }^{7,8}$ Ohya et al. reported the clinical result of ESD using a balloon-assisted technique for 15 cases of difficult lesions. En bloc resection was successfully performed in 13 cases (86.7\%). ${ }^{9}$

In this issue of Clinical Endoscopy, Hermans et al. ${ }^{10}$ performed a retrospective evaluation of clinical results of 63 double-balloon colonoscopies (DBcs) after incomplete colonoscopy, based on comparison with the results of computed tomography colonography. The main reasons of colonoscopic failure include dolichocolon (65\%) and following looping (21\%), combined dolichocolon and looping (8\%), and bowel adhesions (6\%). They reported a 95\% cecal intubation rate, and both diagnostic and therapeutic interventions were performed in $58 \%$ of the cases, including 3 cases of carcinoma. These results suggest that $\mathrm{DBc}$ is an effective tool for completion of colon inspection in incomplete colonoscopy, including therapeutic interventions. These results are in line with the previous reports that demonstrated the clinical efficacy and usefulness of DBc in incomplete colonoscopy. Becx et al. ${ }^{11}$ reported an $88.6 \%$ cecal intubation rate in 104 of 114 patients, and endoscopic polypectomy was performed in 51 patients (44.7\%). Several studies with a relatively small number of patients reported that cecal intubation rates without serious complications ranged from $90 \%$ to $100 \%$ and additional therapeutic interventions were performed in $62 \%$ of the cases. ${ }^{12,13}$

Although the clinical results of $\mathrm{DBc}$ in patients with previously failed colonoscopy seem promising, there are some lim- 
itations. First, balloon assisted enteroscopy is usually equipped in a tertiary referral hospital. Thus, its accessibility is very low, and its high cost is also problematic. Second, considering the diverse endoscopic skill or experience of the each colonoscopist, it is not clear as to which patients can benefit from or be indicated for $\mathrm{DBC}$.

In summary, this study by Hermans et al. showed the effectiveness and safety of DBc for completion of colonic examination and polypectomy after incomplete colonoscopy. ${ }^{10}$ To reduce the developing CRC, qualified colonoscopic examination is essential. Our approach and effort toward qualifying and completeness of colonoscopy should be in part responsible for the reduction of $\mathrm{CRC}$ risk. $\mathrm{DBc}$ can be a valuable tool to achieve this goal.

\section{Conflicts of Interest}

The authors have no financial conflicts of interest.

\section{REFERENCES}

1. Brenner H, Chang-Claude J, Jansen L, Seiler CM, Hoffmeister M. Role of colonoscopy and polyp characteristics in colorectal cancer after colonoscopic polyp detection: a population-based case-control study. Ann Intern Med 2012;157:225-232.

2. Rex DK, Schoenfeld PS, Cohen J, et al. Quality indicators for colonoscopy. Gastrointest Endosc 2015;81:31-53.

3. Radaelli F, Minoli G. Factors associated with incomplete colonoscopy: further information from a large prospective Italian survey. Gastroen- terology 2007;133:1390-1391; author reply 1392.

4. Shah HA, Paszat LF, Saskin R, Stukel TA, Rabeneck L. Factors associated with incomplete colonoscopy: a population-based study. Gastroenterology 2007;132:2297-2303.

5. Rex DK. Achieving cecal intubation in the very difficult colon. Gastrointest Endosc 2008;67:938-944.

6. Mönkemüller K, Weigt J, Treiber G, et al. Diagnostic and therapeutic impact of double-balloon enteroscopy. Endoscopy 2006;38:67-72.

7. Gay G, Delvaux M. Double-balloon colonoscopy after failed conventional colonoscopy: a pilot series with a new instrument. Endoscopy 2007;39:788-792

8. Shimatani M, Takaoka M, Mitsuyama T, et al. Utility of therapeutic ERCP using a newly developed short type single balloon endoscopy in patients with altered gastrointestinal anatomy: comparison of double balloon endoscope and single balloon endoscope. J Gastroenterol Hepatol 2014;29(Suppl 3):298-299.

9. Ohya T, Ohata K, Sumiyama K, et al. Balloon overtube-guided colorectal endoscopic submucosal dissection. World J Gastroenterol 2009;15:60866090.

10. Hermans C, Zee DV, Gilissen L. Double-balloon endoscopy after incomplete colonoscopy and its comparison with computed tomography colonography. Clin Endosc 2018;51:66-71.

11. Becx MC, Al-Toma A. Double-balloon endoscopy: an effective rescue procedure after incomplete conventional colonoscopy. Eur J Gastroenterol Hepatol 2014;26:519-522.

12. Moreels TG, Macken EJ, Roth B, Van Outryve MJ, Pelckmans PA. Cecal intubation rate with the double-balloon endoscope after incomplete conventional colonoscopy: a study in 45 patients. J Gastroenterol Hepatol 2010;25:80-83.

13. Pasha SF, Harrison ME, Das A, Corrado CM, Arnell KN, Leighton JA. Utility of double-balloon colonoscopy for completion of colon examination after incomplete colonoscopy with conventional colonoscope. Gastrointest Endosc 2007;65:848-853. 